\title{
RETRATO DAS DISPUTAS POLÍTICAS NA MÍDIA PONTA-GROSSENSE: análise das estratégias eleitorais na cidade de Ponta Grossa em 2004
}

\author{
Picture of political running in ponta-grossense media: analysis of electoral \\ strategies in the city of Ponta Grossa in 2004
}

\author{
Suelen Fernanda Canguçu Rodrigues ${ }^{a}$, Sérgio Luiz Gadini ${ }^{\mathrm{b}}$ \\ a Jornalista graduada pela UEPG, participante do Programa PIBIC/CNPq no período 2005/06. Ponta Grossa, PR - Brasil, e- \\ mail:suelen_cangucu@yahoo.com.br \\ b Professor de Jornalismo e do Programa de Mestrado em Ciências Sociais Aplicadas/UEPG, coordenador da pesquisa que \\ resultou no presente artigo. Ponta Grossa, PR - Brasil, e-mail: sergiogadini@yahoo.com.br
}

\begin{abstract}
Resumo
A presença da televisão no processo eleitoral, a partir de 1989, aproxima ainda mais comunicação e política. Tal aproximação desloca e integra as regras de funcionamento da linguagem midiática com as estratégias comunicativas do campo político, a fim de tornar o discurso mais apropriado ao eleitor contemporâneo. A crescente midiatização das disputas políticas aumenta, assim, a importância do Horário Político Gratuito Eleitoral (HPGE). O presente artigo analisa os programas transmitidos no HPGE das campanhas eleitorais 2004 no município de Ponta Grossa, estado do Paraná, enfocando as características midiáticas dos candidatos a prefeito e as estratégias de exposição mais utilizadas na busca pelo voto.
\end{abstract}

Palavras-chave: Disputas eleitorais no Paraná; Eleições 2004; Estratégias midiáticas de ação eleitoral.

1 Texto originalmente produzido em pesquisa desenvolvida através do PIBIC/CNPq/UEPG 2005/06. O artigo integra uma pesquisa em andamento (sob o título "Retrato das disputas políticas na mídia paranaense"), que conta com apoio do CNPq. 


\begin{abstract}
The television's presence on electoral process, from 1989, more approaches communication and politic. That approach dislocates and integrates the rules of functioning of mediatic language with the communication estrategies of political field, with a goal to become a discourse more apropriate to the contemporary elector. The growing mediatisation of potilical running increases, thus, the importance of Horário Politico Gratuito Eleitoral (HPGE). This essay analyses the broadcasting programmes on HPGE in 2004 electoral campaign in the city of Ponta Grossa, Parana State, which focuses the mediatic characteristics of candidates to mayor and strategies of exposition more usefull on running for the vote.
\end{abstract}

Keywords: Electoral running in Paraná; 2004 elections; Mediatic strategies of electoral action.

\section{CONSIDERAÇÕES PRELIMINARES}

A partir de 1989, com a maior aproximação entre comunicação e política, a propaganda eleitoral passa a depender da exposição na mídia. A suposta distância entre os dois campos (político e midiático) leva os candidatos a redefinirem suas estratégias comunicativas. Ou seja, quando a propaganda política se transforma em tele-propaganda impõe regras do funcionamento da linguagem midiática aos que querem tornar-se apropriados ao gosto e simpatia do eleitor acostumado ao império da imagem e à cultura dos spots no mundo contemporâneo.

Para adequar as estratégias ao meio entram em cena publicitários, políticos e especialistas em marketing político. Tais profissionais introduzem recursos que dão suporte imagético aos discursos, buscando deixar mais leves algumas partes inevitavelmente discursivas ou até mesmo pesadas. Para isso, usam formatos de telejornais, talk shows e programas de auditório conduzidos por personalidades; usam o recurso da teledramaturgia para traduzir mensagens; e introduzem videoclipes para buscar a memorização de propostas e número dos candidatos.

A propaganda política midiática segue, assim, o modelo de linguagem da publicidade. Ela não vende o candidato pelo que ele é ou pelas suas propostas (persuasão por meio de argumentos), mas principalmente pelo uso da gramática e do ritmo adequados ao homem contemporâneo. De acordo com Heloísa Matos (1994, p. 18), nas campanhas eleitorais, "o candidato é julgado mais pela sua competência comunicativa do que política". Os aspectos estéticos e retóricos das mensagens tornam-se mais importantes do que o conteúdo da propaganda propriamente dito.

Com a crescente midiatização das sociedades parece cada vez mais difícil pensar em disputas políticas sem a presença da mídia. De acordo com Rubens Figueiredo (1994, p. 78), "quem baseia sua campanha apenas em programas [de governo] bem elaborados, dificilmente pode ter chances. A política como espetáculo ganha cada vez mais espaço no mundo inteiro."

O elevado custo do palanque eletrônico gera, evidentemente, um grande problema aos candidatos porque limita o tempo de exibição. Tal obstáculo é, em parte, ${ }^{2}$ superado por meio do Horário Político Gratuito Eleitoral (HPGE) que procura evitar que as vantagens econômicas transformemse diretamente em vantagens políticas.

Nessa perspectiva, o HPGE tem grande influência junto à opinião pública e na escolha dos eleitores. No entanto, existe uma lacuna nas pesquisas sobre política que incorporam com nitidez as estratégias midiáticas, especialmente da TV, como variável significativa no processo eleitoral. Ainda são poucos os estudos eleitorais no Brasil e, em especial, no Paraná.

\footnotetext{
Em parte porque, além dos candidatos terem tempos diferentes de exposição, os palanques midiáticos da tele-propaganda transformam a política em uma atividade sofisticada e aumentam a importância do financiamento das campanhas para a contratação de marketólogos e preparação dos programas que serão exibidos no HGPE.
} 
Diante desta constatação, um grupo de pesquisadores $^{3}$ se reuniu com o objetivo de identificar as características predominantes e comparar as dinâmicas das campanhas eleitorais de 2004 nos municípios de Curitiba, Londrina, Maringá e Ponta Grossa, a partir do HPGE televisivo. Com base no número de eleitores, na cobertura do território do Estado e na posição que ocupam como pólos regionais essas quatro cidades podem ser consideradas suficientes para uma amostragem das relações entre a mídia e a política paranaense. Deve-se ter, ao término da investigação, um "Retrato da disputa político-eleitoral no Paraná”.

Nesse quadro, a proposta do artigo (Retrato das atuais disputas politicas na mídia pontagrossense: análise das estratégias eleitorais na cidade de Ponta Grossa em 2004) é identificar as estratégias discursivas mais frequentes nas disputas expressas no HPGE televisivo de Ponta Grossa na primeira eleição municipal com disputa em dois turnos.

\section{Orientações metodológicas}

Todos os programas noturnos do HPGE, dos candidatos à majoritária, de Ponta Grossa, exibidos nos dias 15, 17, 20, 22, 24, 27 e 29 de setembro (primeiro turno) e 18, 19, 20, 21, 22, 25, 26, 27, 28 e 29 de outubro de 2004 (segundo turno), foram assistidos pelas então integrantes do Programa PIBIC/CNPq-UEPG, Suelen Canguçu e Adrielle Costa, divididos em segmentos - entendendo que um segmento é uma unidade independente, seja em termos de formato, seja em termos de conteúdo - e catalogados.

A coleta dos dados foi feita com base na categorização definida em encontros do Grupo de Pesquisa em Mídia, Política e Atores Sociais para análise do HGPE dos candidatos às eleições majoritárias e proporcionais em 2004 nos quatro municípios do Paraná.

Cada um dos segmentos dos programas foi analisado pelas estratégias discursivas utilizadas. As típicas de mandatário (geralmente usadas por aquele que está no poder); uso do cargo, postura acima da "briga" (quando o candidato não se envolve em discussões com o seu oponente), associação à administração em curso/ênfase em realizações, endosso de lideranças, endosso do patrono político, menção ao partido ou coligação; e as típicas de desafiante (geralmente usadas por aquele que se opõe ao que está no poder); apelo a mudanças, ofensiva quanto a temas, ataques à administração em curso, ataques aos adversários.

A partir daí, cada segmento também foi classificado pelo objeto tratado: políticas públicas (segurança pública, saúde, educação, tributos, infraestrutura e saneamento básico, desenvolvimento/planejamento urbano, esporte, cultura e lazer, transporte, meio ambiente, emprego, orçamento, criança, idoso, mulher, funcionalismo), construção de imagens (da cidade, do estado, do país, do candidato, do partido, do adversário, do eleitor) e meta campanha (pesquisa eleitoral, cenas de campanha, apelos ao engajamento do eleitor, pedagogia do voto, exposição de comícios, festas, debate, agenda do candidato, irregularidade na campanha).

De acordo com o objeto, o conteúdo foi qualificado pela dimensão temporal (passado/ presente, futuro, indefinido), valência da referida dimensão (positiva, negativa, neutra) ou pelo atributo do candidato/adversário (pessoal, político, administrativo) e a valência do mesmo atributo (positiva, negativa, neutra).

Os segmento foram ainda classificados pelo formato escolhido: pronunciamento do candidato, pronunciamento do candidato a vice, documentário, telejornal, entrevista, vídeo clipe/ jingle, ilustração/animação, dramatização/ ficção, "povo fala", depoimentos e chamada (âncora anuncia o que será mostrado a seguir).

Pelo orador dominante, os segmentos foram qualificados em música instrumental, candidato, candidato à vice, patrono político, garoto propaganda, âncora, líder partidário, off ${ }^{4}$ do locutor, off do cantor, popular, personagem/ ficção, personalidade.

De acordo com o apelo, os segmentos foram considerados como pragmático (apresentação de proposta), ideológico (identificação do eleitor pela ideologia do candidato), político (críticas ao

\footnotetext{
O grupo de Pesquisa Mídia, Política e Atores Sociais surgiu, em 2004, a partir de um projeto de estudo sobre o "Retrato das atuais disputas político-eleitorais no Estado do PR", formado por professores e acadêmicos dos cursos de graduação em Jornalismo, Direito e do mestrado em Ciências Sociais Aplicadas (UEPG), sob coordenação de Emerson Urizzi Cervi e Sérgio Luiz Gadini.

4 Off“é o texto gravado pelo repórter sem que o rosto dele esteja no vídeo. As imagens devem mostrar coisas ou pessoas relacionadas ao assunto abordado. O repórter vai conduzindo a matéria com uma narração que deve ser objetiva e dinâmica" (PRADO, 1996, p. 28).
} 
plano de governo do adversário ou ênfase em realizações), emocional (sensibilização do eleitor) ou documental (inserção de pessoas com credibilidade para enaltecer o candidato).

Pela retórica, os segmentos foram qualificados em proposição (projeção de idéia), crítica (desqualificação do adversário), valores (referências morais do candidato), ameaça (rejeição do adversário) ou adesão (argumento de apoio ao candidato).

E pela linguagem os segmentos foram classificados em: didática (explicativa), informativa (dar informações, dados relevantes), panfletária (uso de estereótipos, chavões, clichês) e propaganda (propagação de idéias, valores, conceitos, imagens).

\section{Indicadores de análise}

De acordo com Rubens Figueiredo (1994, p. 79), "no Brasil, as pesquisas tem mostrado que, progressivamente, o eleitorado vem se preocupando mais com o(a) candidato(a) do que com o partido e outras questões." Coincidência ou não, grande parte do HPGE de Ponta Grossa em 2004 foi dedicado à produção de imagens dos candidatos.

De modo geral, as formas dramáticas e emocionais, construídas segundo o modelo do entretenimento, foram as preferidas pelos coordenadores de campanha para adequaro discurso político à dimensão espetacular da televisão.

Prevaleceu o apelo emocional (44\%), a retórica de adesão $(46 \%)$ e a linguagem panfletária $(42 \%)$. Além disso, os formatos mais utilizados foram "povo fala" (28\%), depoimentos $(22 \%)$ e pronunciamento do candidato $(20 \%)$, consequentemente, os oradores dominantes foram populares $(28 \%)$, o candidato $(20 \%)$ e personalidades $(16 \%)$.

Em outros termos, os programas dedicaram mais espaço para sensibilizar o eleitor, para enaltecer o candidato e para enfatizar realizações ou desqualificar os adversários do que para identificar as referências ideológicas ou apresentar as idéias e propostas dos candidatos. E, fizeram isso por meio da argumentação do povo, de pessoas com credibilidade social e do próprio candidato, usando estereótipos e valores.

\section{Aspectos técnicos e apresentação do conteúdo}

O candidato Péricles de Holleben Mello $(\mathrm{PT})^{5}$ foi quem mais investiu na campanha (R\$ $\left.1.190 .127,63^{6}\right)$. Parte deste valor foi gasto com o HPGE e resultou em programas de alta qualidade técnica. No primeiro turno, os mais de 10 minutos de exposição que teve em cada um dos sete dias de propaganda televisiva dedicados à campanha majoritária (que foi analisada na amostra do presente estudo) no primeiro turno foram divididos em 24 segmentos, em média, sendo que nenhum programa foi reapresentado na íntegra.

$\mathrm{Na}$ maioria dos segmentos, Péricles adotou um tom "neutro", buscando ignorar os outros candidatos. Ele manteve postura acima da briga em 91\% dos segmentos, em 7\% atacou os adversários e em 4\% foi ofensivo quanto a temas. Em uma das vezes em que um ataque foi feito a um adversário apenas foi transportada uma crítica dos jornais para a mídia eletrônica. A estratégia de indiferença, pela lógica, seria mais adequada para o candidato que estava em primeiro lugar e não deveria se envolver em polêmicas. No caso de Péricles, não bastava expor suas idéias; era necessário dizer que as suas eram melhores do que as do outro candidato. Expor as realizações da administração em curso, que foram constatadas em $42 \%$ dos segmentos, também pode não ter sido a melhor estratégia, uma vez que o índice de aprovação de seu Governo não era tão $\mathrm{alto}^{7}$ e o índice de rejeição estava na casa dos $30 \% .^{8}$

\footnotetext{
5 A Coligação União Popular por Ponta Grossa era formada por diversas legendas partidárias: PDT/PT/PTB/PMDB/PSL/ PTN/PCB/PSDC/PRTB/PMN/PSB/PV/PRP/PC do B/PT do B.

${ }^{6}$ Valor declarado no TRE/PR, inclui os gastos totais do primeiro e segundo turnos.

Pesquisa Diário dos Campos/CBN/Mundi, realizada pelo Instituto Experience, de Curitiba, realizada entre os dias 31 de agosto e $1^{\circ}$ de setembro de 2004 onde foram entrevistados 400 ponta-grossenses. Destes 6,5\% avaliaram a administração do prefeito Péricles de Holleben Mello até o momento como ótima, 35,5\% como boa, 40\% como regular, 7,3\% como ruim e 9,5\% como péssima.

8 Pesquisa Diário dos Campos/CBN/Mundi, realizada pelo Instituto Experience, de Curitiba, registrada sob o número 75/ 04 na $14^{\text {a }}$ Zona Eleitoral do Fórum de Ponta Grossa. O Instituto Experience ouviu 400 eleitores de Ponta Grossa entre os dias 28 e 29 de setembro. A margem de erro da pesquisa é de 4,9 pontos percentuais para mais ou para menos.
} 
Para amenizar tais fatos, Péricles apostou no testemunho de personalidades e na fala de populares, aprovando o seu mandato e apoiando a sua candidatura. O endosso de lideranças apareceu, assim, em $24 \%$ de seus segmentos e outros $30 \%$ foram abertos para os seus eleitores.

Em 7\% dos segmentos, Péricles fez menção ao partido, ressaltando que o PT representava o homem "comum", a maioria da população. Aliás, foi esse perfil que o candidato adotou em seus discursos: o homem da rua, a vitória do cidadão médio. E explorou essa imagem muitas vezes. A construção da imagem do prefeiturável foi o objeto principal em $27 \%$ dos segmentos da propaganda petista. Pela classificação de Joan Férres (1996, p. 165), pode-se dizer que o candidato Péricles Mello se enquadraria no herói de série B da política. ${ }^{9}$

Seus marketólogos parecem ter seguido à risca a classificação de FÉRRES (1996, p. 158) de se atribuir menos importância aos argumentos e aos fatos e mais importância para a atração da imagem pessoal e a manipulação dos símbolos e das emoções na disputa. Nos programas predominaram as formas de apelo documental (31\%) e emocional (21\%), além da retórica de adesão (49\%). Em um dos segmentos o candidato chega a recitar um poema $\mathrm{e}$ em muitos outros pede voto ao eleitor.

$\mathrm{O}$ uso de linguagem propagandística $(37 \%)$ e panfletária $(25 \%)$ revela a transposição de características do marketing de produtos para o marketing político em uma tentativa de adequar o discurso político à cultura televisiva.

Os pronunciamentos de Péricles Mello eram longos (alguns com mais de três minutos) e se enquadravam no tipo "cardápio", termo utilizado quando o orador fala sobre muitos temas sem se centrar em nenhum. Aqui, uma das primeiras regras da comunicação política, a da USP (Unique Selling Proposition - Única Proposição de Venda), era esquecida. Ao invés de em cada spot gravado pelo candidato ser vendida apenas uma idéia, apenas uma proposição, uma variedade de políticas públicas era abordada.

No segundo turno, o candidato manteve uma postura "neutra". Entrou na briga com o adversário em $2 \%$ dos segmentos. Mas fez menos associações a administração em curso (11\%) e outras menções ao partido (16\%). Manteve falas dos eleitores $(29 \%)$ e os depoimentos de pessoas com credibilidade (28\%). Apostou, ainda mais, nas linguagens panfletária (53\%) e propagandística $(32 \%)$ e nos argumentos de adesão ao candidato $(71 \%)$. A maior mudança foi no apelo. A sensibilização emocional do eleitor predominou em $60 \%$ dos segmentos.

\section{Valorização do conteúdo em detrimento da estética}

Luiz Setembrino Von Holleben, candidato do $\mathrm{PP},{ }^{10}$ adotou um tom polêmico. Utilizou estratégias discursivas típicas de desafiante, atacando a administração em curso logo no primeiro programa transmitido.

Do total, em 23\% dos segmentos o candidato entrou na briga, em 19\% fez ofensiva quanto a temas, em 14\% fez apelo a mudanças, em 14\% atacou a administração em curso e em $14 \%$ atacou os adversários. Tal postura implicou na perda de parte do tempo na TV para cumprir decisões do Tribunal Regional Eleitoral (TRE/ $\mathrm{PR}$ ), que concedeu parte do horário do PP a um dos adversários para contestar as acusações e insinuações veiculadas no HPGE de Setembrino.

Em 38\% do HPGE o candidato do PP foi o próprio orador dominante. Característica interessante, na medida em que Setembrino buscava uma linguagem didático-educativa $(20 \%)$ esclarecendo o eleitor, por exemplo, sobre o Tribunal de Contas, embora recorrendo com frequência à linguagem informativa (45\%).

$\mathrm{Na}$ maioria dos segmentos (47\%), o candidato apostou no formato "povo fala", onde seus eleitores ora apareciam fazendo perguntas (as quais ele respondia didaticamente), ora se pronunciando em favor do candidato, fazendo elogios e valorizando seus atributos pessoais. Os apelos variaram entre políticos $(40 \%)$, pragmáticos $(30 \%)$ e emocionais $(30 \%)$, e a retórica do candidato oscilava entre propositiva (45\%) e crítica $(25 \%)$.

\footnotetext{
9 É o governante que provoca a adesão poridentificação, o político que satisfaz as exigências de igualdade. É o presidente-espelho: é como um de nós. É a revanche dos simples. É o homem comum que encarna as virtudes comuns (FÉRRES, 1996, p. 165). ${ }^{10}$ Coligação Mudança pra Valer (PP/PAN).
} 
Deste modo, o programa televisivo do PP em PG/2004 parecia ganhar no quesito conteúdo, mas perder em estética, talvez pelo uso frequente de discursos longos e com pouca variação nos formatos. Provavelmente, tal característica está associada ao pouco tempo de exposição (menos de quatro minutos) e a um orçamento mais modesto ( $\mathrm{R} \$ \quad 61.564,65^{11}$ ) que obrigava um planejamento de programas mais simples, com menos segmentos (média de apenas três), e a reexibição de um programa (o do dia 15 de setembro, por exemplo, foi re-exibido dois dias depois).

\section{Dificuldades no uso de estratégias midiáticas}

O candidato Paulo Bohaienko Sobrinho (PSC) demonstrou dificuldades para se adaptar à gramática do meio televisivo. Em $95 \%$ dos segmentos o formato utilizado foi pronunciamento do próprio candidato. Embora fosse nítido o tom de leitura, os discursos pareciam ter sido escritos por terceiros.

Aqui é oportuna fazer uma relação com o que diz Pierre Bourdieu (1998, p. 169) sobre a tradição dos atores políticos:

O babitus do político supõe uma preparação especial. É, em primeiro lugar, toda a aprendizagem necessária para adquirir o corpus de saberes específicos (teorias, problemáticas, conceitos, tradições históricas, dados econômicos etc.) produzidos e acumulados pelo trabalho políticodos profissionais do presentee do passado ou das capacidades mais gerais tais como o domínio de uma certa linguagem e de uma certa retórica política, a do tribuno, indispensável nas relações com os profanos, ou a do debater, necessária nas relações com os profissionais.

Com a midiatização da política cabe acrescentar aqui a necessidade de conhecimento da linguagem televisiva. No HPGE da disputa pela Prefeitura de PG em 2004, Paulo Bohaienko tratou de assuntos como políticas públicas nas áreas de segurança pública, educação, desenvolvimento urbano e inclusão social. Acontece que, "muitas vezes, a maneira de falar as coisas é mais importante que a mensagem e a intenção do(a) candidato(a)"
(FIGUEIREDO, 1994, p. 83). E parece ter faltado uma visão estratégica para melhor aproveitar a retórica de proposição $(73 \%)$ e os apelos político $(47 \%)$ e pragmático $(47 \%)$ que predominaram nos segmentos do candidato.

\section{Fazer crer que se pode fazer o que se diz}

O candidato eleito, Pedro Wosgrau Filho $\left(\right.$ PSDB $^{12}$ ), além de ter quase oito minutos de exposição, teve um financiamento de $\mathrm{R} \$$ $912.042,23 .{ }^{13} \mathrm{E}$, ao que tudo indica, foi o candidato que melhor aproveitou o suporte televisivo. Em todos os programas, falou em tom de conversa, centrado em um objeto.

"Em política, 'dizer é fazer', quer dizer, fazer crer que se pode fazer o que se diz" (BOURDIEU, 1998, p. 185) e, no primeiro turno, Wosgrau conseguia transmitir uma visível veracidade em suas promessas, tanto pela sua estratégia discursiva quanto pela capacidade de fazer crer na sua autoridade. Para isso, o candidato adotou uma postura "paternal" com uma postura de 'sabedoria' e moderação para o discernimento adequado em épocas de crises (FÉRRES, 1996). A construção da imagem foi o que mais ocupou o tempo em seus programas $(23 \%)$.

Como esteve durante toda a campanha em primeiro lugar nas pesquisas,${ }^{14}$ estrategicamente poderia ter se mantido acima da discussão política com os adversários, mas em 7\% dos segmentos ele entrou na briga, respondendo ou fazendo críticas à administração em curso e/ou aos adversários.

Wosgrau também contou com o endosso de lideranças $(17 \%)$ e abriu espaço para seus eleitores $(26 \%)$ que o ajudaram a relembrar suas realizações enquanto prefeito de Ponta Grossa e a pedir votos. $\mathrm{O}$ formato de telejornal, a introdução de vídeo-clipes e a inserção de pronunciamentos do candidato à vice e da esposa de Wosgrau, Isabel Wosgrau, pareciam ainda contribuir para que os programas não fossem cansativos.

Os apelos ficaram divididos entre emocionais $(33 \%)$, documentais $(25 \%)$ e políticos $(23 \%)$. A retórica propositiva aparece em 36\% dos segmentos e a de adesão em 31\%. Prevalece, assim, a linguagem de propaganda (50\%).

\footnotetext{
${ }^{11}$ Valor declarado no TRE/PR.

${ }^{12}$ Coligação Vamos Trabalhar Juntos (PFL/PTC/PSDB)

${ }^{13}$ Valor declarado no TRE/PR.

${ }^{14}$ Quatro pesquisas Diário dos Campos/CBN/Mundi, realizadas pelo Instituto Experience, de Curitiba e três pesquisas RPC, realizadas pelo IBOPE.
}

Rev. Estud. Comun., Curitiba, v. 9, n. 19, p. 147-154, maio/ago. 2008 
No segundo turno, o candidato muda de postura. Entra na briga em 34\% dos segmentos, faz apelo a mudanças em $12 \%$, opta pela ofensiva quanto a temas em $11 \%$, ataca a administração em curso em $39 \%$ e ataca o adversário em $28 \%$. Wosgrau também faz menção as novas alianças em 19\% dos segmentos.

Os oradores foram mantidos: os eleitores falaram em 31\% dos segmentos, o candidato em $23 \%$ e personalidades em $20 \%$. No entanto, predominou o apelo emocional $(65 \%)$, as retóricas de adesão $(46 \%)$ e de crítica $(32 \%)$ e a linguagem panfletária $(67 \%)$.

\section{Valorização da estética em detrimento do conteúdo}

João Carlos Barbiero ( $\mathrm{PL}^{15}$ ) foi um dos candidatos que menos ${ }^{16}$ investiu na campanha $\left(\mathrm{R} \$ 51.910,35^{17}\right)$. Seu programa no HGPE, de pouco mais de três minutos por dia, foi composto, em média, por seis segmentos, dedicados para criar a imagem do líder sedutor ${ }^{18}$ (o atributo pessoal predominou em $83 \%$ dos segmentos em que o objeto era a imagem do candidato) e para convencer o eleitorado de que ele tinha chances de ficar entre os dois candidatos mais votados e vencer o segundo turno.

Ele praticamente não fez apelo a mudanças $(2 \%)$, não atacou a administração em curso e foi moderado ao criticar os adversários $(13 \%)$. No entanto, também não se dedicou à apresentação de propostas, mais de 50\% dos seus segmentos foram de apelos ao engajamento do eleitor. Outros 9\% do HPGE do PL foram dedicados à construção da imagem do eleitor.

Barbiero pronunciou-se em 33\% dos segmentos de seus programas, geralmente com falas de um minuto ou mais. Também abriu a câmera para os eleitores falar em $41 \%$ dos segmentos, mas com tempos bem curtos, reduzido em poucos segundos. E o formato de vídeo-clipe ocupou 10\% dos segmentos. No geral, predomina o apelo emocional $(89 \%)$, a retórica de adesão $(66 \%)$ e a linguagem panfletária (67\%).

\section{Manchar a imagem dos adversários}

Leopoldo Cunha Neto, candidato do PPS, ${ }^{19}$ gastou na campanha $\mathrm{R} \$ 61.564,65 .{ }^{20} \mathrm{O}$ programa do HPGE de TV tinha aproximadamente dois minutos de duração por dia e era dividido em seis segmentos, em média.

O prefeiturável do PPS usa estratégias típicas de desafiante (24\%): faz apelo à mudança $(12 \%)$ e ataca adversários (24\%), inicialmente, por meio do personagem "Mister W" (o que lhe rende suspensão de 30 segundos do programa do dia 22 de setembro) e, depois, por meio do discurso do próprio candidato.

Ao contrário dos candidatos Péricles, Wosgrau e João Barbiero que, criaram imagens de heróis para si, Leopoldo se preocupa em criar um lado perverso para cada um deles. Provavelmente, a idéia que conduziu sua campanha foi a de que uma eleição não se ganha apenas mostrando os pontos fortes do candidato, mas também ressaltando os defeitos de seus adversários. FIGUEIREDO (1994, p. 54), oportunamente, alerta que "o eleitorado resiste quando se ultrapassa certos limites."

$\mathrm{Na}$ disputa de 2004 em Ponta Grossa, Leopoldo dedica 25\% dos segmentos do HPGE para fazer apelos ao eleitorado, 20\% para construir sua imagem através de depoimentos, 17\% para construir a imagem do seu eleitor e 15\% para criar uma imagem negativa dos adversários, quase não sobrando tempo para expor suas propostas.

O formato de depoimentos foi o mais usado $(24 \%)$, seguido do pronunciamento do candidato $(19 \%)$ e do "povo fala" (15\%). O apelo emocional $(52 \%)$ foi o mais frequente. E a retórica de adesão teve $45 \%$ de frequência, enquanto valores e críticas ficaram empatadas com $20 \%$. As linguagens panfletária e propagandística estiveram presentes em $46 \%$ e $49 \%$ dos segmentos, respectivamente.

\footnotetext{
${ }_{15}^{15}$ Coligação Ponta Grossa tem Futuro (PL/PRONA).

${ }^{16}$ O candidato Paulo Bohaienko está em dívida com o TRE/PR porque ainda não prestou contas e pode, portanto, ter investido um valor menor na campanha do que o candidato do PL.

${ }^{17}$ Valor declarado no TRE/PR.

${ }^{18} \mathrm{Na}$ concepção de Joan Ferres (1996, p. 165), “o sedutor é o líder encantador, que cativa mais do que convence, frequentemente com um ar jovial e dândi. Agrada, surpreende, faz sonhar. É o irmão solidário em uma época de abundância e paz.”

${ }^{19}$ Coligação Caminhada para Mudança (PPS / PHS).

${ }^{20}$ Valor declarado no TRE/PR.
} 
Ou seja, mesmo com a estratégia de depreciação aos adversários feita em linguagem publicitária, havia, na produção, uma outra forma de publicidade - negativa, mas, ainda assim, publicidade.

\section{CONSIDERAÇÕES FINAIS}

O uso da linguagem midiática no HPGE televisivo de 2004 em Ponta Grossa ainda está em caráter embrionário. Tanto os candidatos como os publicitários que os orientam ainda buscam melhor compreender o objetivo da telepropaganda político-eleitoral e as estratégias comunicativas que podem ser exploradas.

A preferência pelo uso de linguagem panfletária e propagandística mostra que, na tentativa de adequar o discurso político à cultura televisiva, opta-se pela transposição de características do marketing de produtos para o marketing político. Aspecto este também perceptível na personalização da política. $\mathrm{Na}$ maioria dos segmentos do HPGE 2004 em Ponta Grossa registrou-se uma prioridade à construção e apresentação da imagem dos candidatos, da criação de um rótulo para os próprios atores da disputa.

Se, por um lado, isso revela uma preocupação em se adequar à gramática do veículo e às exigências do eleitor que convive com a mídia eletrônica, por outro lado, o fato dos programas do HPGE televisivo não conseguirem apresentar as propostas dos candidatos de forma competente, com clareza e convencimento, demonstra ou uma carência dos profissionais ou dos próprios políticos.

Daí a justificativa do presente texto - e, pois, da pesquisa - na busca da identificação das principais estratégias eleitorais no HPGE, tomando por base os programas veiculados na disputa municipal de Ponta Grossa em 2004. Mesmo sem condições de generalizar o estudo para outras situações pontuais, trata-se de um desafio para (re)pensar os modos de fazer política na era da sociedade midiática.

\section{REFERÊNCIAS}

BOURDIEU, Pierre. O poder simbólico. Rio de Janeiro: Bertrand Brasil, 1998.

FÉRRES, Joan. Televisão subliminar. Porto Alegre: Artmed, 1996.

FIGUEIREDO, Rubens. O que é marketing político. São Paulo: Brasiliense, 1994.

MATOS, Heloísa. Agenda temática da pesquisa em comunicação política. In: MATOS, Heloísa (Org.). Mídia, eleições e democracia. São Paulo: Página Aberta, 1994. p. 13-30.

PRADO, Flávio. Ponto eletrônico. São Paulo: Publisher Brasil, 1996.

Recebido: 14/05/2008

Received: 05/14/2008

Aprovado: $30 / 05 / 2008$

Approved: 05/30/2008 